\title{
Novel Hsp90 Inhibitor C086 Potently Inhibits Non-Small Cell Lung Cancer Cells As A Single Agent Or In Combination With Gefitinib
}

This article was published in the following Dove Press journal: Cancer Management and Research

\author{
Liman Wang ${ }^{1-3, *}$ \\ Yingjuan Fan ${ }^{1}, *$ \\ Hanhao Mei ${ }^{\prime}$ \\ Yang Liu' \\ Lianru Zhang ${ }^{4}$ \\ Jianhua $X u^{\prime}$ \\ Xuhui Huang ${ }^{2,3}$ \\ 'Institute of Materia Medica, School of \\ Pharmacy, Fuijan Provincial Key \\ Laboratory of Natural Medicine \\ Pharmacology, Fujian Medical University, \\ Fuzhou 350 122, People's Republic of \\ China; ${ }^{2}$ Department of Pharmacy, Fujian \\ Provincial Hospital Jinshan Branch/Fujian \\ Provincial Hospital South Branch, Fuzhou \\ 350028, People's Republic of China; \\ ${ }^{3}$ Provincial Clinical Medical College of \\ Fujian Medical University, Fuzhou 350000, \\ People's Republic of China; ${ }^{4}$ State Key \\ Laboratory of Cellular Stress Biology, \\ School of Life Science, Xiamen University, \\ Xiamen 36/005, People's Republic of \\ China
}

*These authors contributed equally to this work
Purpose: Inhibition of heat shock protein 90 (Hsp90) can lead to degradation of multiple client proteins, which are involved in tumor progression. Elevated Hsp90 expression has been linked to poor prognosis in patients with non-small cell lung cancer (NSCLC). Discovery of effective drug is a promising strategy to improve patient survival. This study aims to investigate the synergistic antitumor mechanism of C086 combined with gefitinib in NSCLC cells in vitro.

Methods: The binding of C086, gefitinib, and the combinations to Hsp90 was characterized by fluorescence quenching experiments. The inhibition of A549 or NCI-H1975 cell proliferation and apoptosis by $\mathrm{C} 086$ and gefitinib as a single agent or in combinations were performed using CFSE staining assays, AnnexinV-APC/PI and Western blot.

Results: C086 alone or with gefitinib reduces proliferation and increases proapoptotic caspase activation of both wild-type and mutation NSCLC, with NCI-H1975 cells showing much greater sensitivity to $\mathrm{C} 086$ and the combinations than A549 cells. The combination of C086 and gefitinib showed synergistic reduction of EGFR expression and the downstream PI3K/Akt and Ras-Raf-Erk pathways enhanced suppression of Erk signaling.

Conclusion: C086 combined gefitinib has a good synergistic antitumor effect in vitro. Therefore, the combination of $\mathrm{C} 086$ and gefitinib may provide a new theoretical basis and ideas for the treatment of NSCLC patients.

Keywords: C086, Hsp90 inhibitor, EGFR, non-small cell lung cancer

\section{Introduction}

Lung cancer is the most common cause of cancer death throughout China and the world. ${ }^{1,2}$ Over $80 \%$ of lung cancer patients belong to the non-small cell lung cancer (NSCLC) group with a poor prognosis. ${ }^{3}$ The elevated overall epidermal growth factor receptor (EGFR) kinase activity, as a result of the increased amount and/or the gainof-function mutations, plays a key role in the disease progression and cancer malignancy. ${ }^{4}$ These offer an effective therapeutic target to develop agents for NSCLC. ${ }^{5}$ Gefitinib, EGFR-tyrosine kinase inhibitor (TKI), is the approved therapy for NSCLC harboring EGFR with activating mutations. ${ }^{6-8}$ Unfortunately, those who respond to gefitinib at the early stages develop resistance because of the emergence of EGFR mutations or other genomic alterations with wild-type EGFR, including K-ras mutations. ${ }^{9,10}$ Circumventing the resistance to TKI is actually the most formidable challenge in treating NSCLC patients. Thus, identification of an effective treatment using rationalized combinations of agents is particularly promising.
Correspondence: Jianhua Xu Institute of Materia Medica, School of Pharmacy, Fuijan Provincial Key Laboratory of Natural Medicine Pharmacology, Fujian Medical University, No. I, Xue Fu Bei Road, University Town Fuzhou 350122, People's Republic of China

$\mathrm{Tel} / \mathrm{Fax}+86 \quad 13338440289$

Email xjh@fjmu.edu.cn 
Heat shock protein 90 (Hsp90) is a highly conserved molecular chaperone that plays an important role in the maturation and stabilization of over 200 oncogenic client proteins $^{11,12}$ and is considered to be an attractive target for cancer therapies. ${ }^{13-15}$ Most Hsp90 client proteins, such as EGFR, Akt and C-Raf, are crucial for growth, differentiation and survival of tumors. ${ }^{16-18}$ Increased HSP90 expression has been linked to worse prognosis in patients with NSCLC. ${ }^{19}$ To achieve synergistic treatment, Hsp90 inhibitor was chosen as another chemotherapeutic drug.

In our previous work, ${ }^{20-22}$ we identified a novel potent Hsp90 inhibitor, 4-(4-hydroxy-3-methoxy-phenyl-methyl) curcumin (C086) (Figure 1A), which could inhibit cell cycle progression and induce cell apoptosis and antimetastasis by regulating various mechanisms in different cell types. Although the anticancer mechanisms of C086 and the antineoplastic activities of C086 combined with several clinical used antitumor drugs have been documented, ${ }^{23}$ the potential effects of $\mathrm{C} 086$ combined with gefitinib in NSCLC have not been investigated. In this study, two NSCLC cell lines A549 and NCI-H1975 were used to evaluate the properties of $\mathrm{C} 086$ alone and its combination with gefitinib on cell growth. Herein, we reveal potent antitumor activity of $\mathrm{C} 086$ as a single agent and in combination with gefitinib, which exhibited synergetic effects on inhibition of cell proliferation and enhanced apoptosis by modulating the EGFR protein kinase activity in NSCLC in vitro.

\section{Materials And Methods}

\section{Cell Lines, Plasmids And Reagents}

The human NSCLC cell lines A549 and NCI-H1975 were obtained from the Cell Bank of the Chinese Academy of Sciences (Shanghai, China). The cells were cultured in

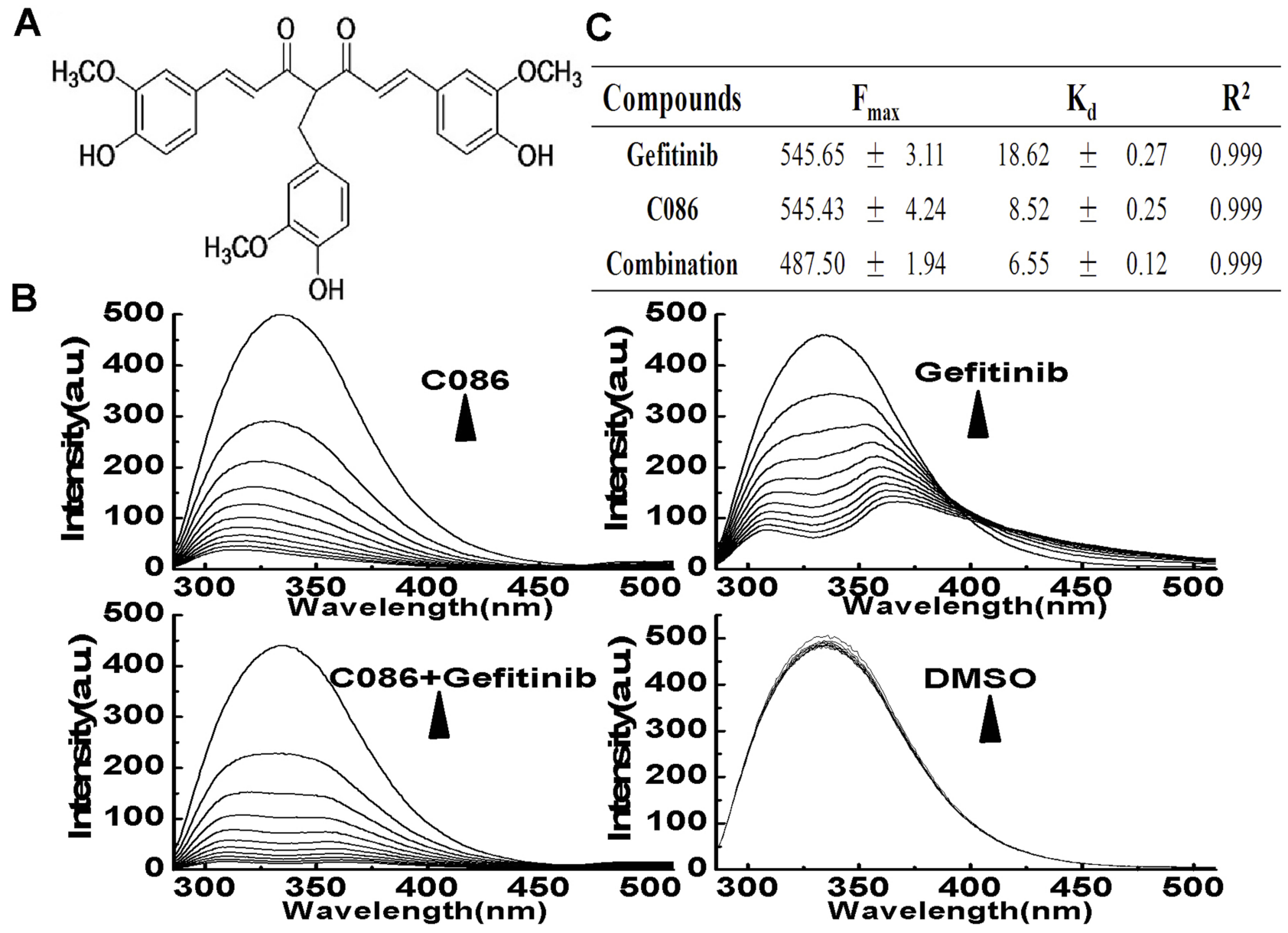

Figure I C086, gefitinib, and the combinations physically binds to the Hsp90 and disrupts its Hsp90 chaperone function. (A) Chemical structure of C086, 4-(4-hydroxy-3methoxy-phenyl-methyl) curcumin. (B) The fluorescence quenching spectra of Hsp90 with C086 (ranging from 5.0 to $50 \mu$ mol/L) and gefitinib as single agents or in combinations at different concentration. The concentration of $\mathrm{Hsp} 90$ was fixed at $5.0 \mu \mathrm{mol} / \mathrm{L}$, and the ratio of C086, gefitinib, and the combinations vs $\mathrm{Hsp} 90$ was from I:I to I0:I. The vertical and horizontal axes represent the fluorescent intensity and emission wavelength, respectively. The excitation wavelength is $280 \mathrm{~nm}$, whereas the $\mathrm{Hsp} 90$ emission peak is at $337 \mathrm{~nm}$. (C) The $F_{\max }, K_{d}$ of C086, gefitinib, and the combinations. The results represent the mean $\pm S E M$ of triplicate experiments. 
RPMI-1640 media containing 10\% fetal bovine serum, $100 \mathrm{U} / \mathrm{mL}$ penicillin, and $100 \mathrm{mg} / \mathrm{mL}$ streptomycin at $37^{\circ} \mathrm{C}$ in a humidified atmosphere of $5 \% \mathrm{CO}_{2}$.

The bacterial strains and plasmids were obtained from the School of Life Science of Xiamen University, China. C086 (purity $\geq 99 \%$ ) was designed and synthesized by our laboratory (Figure 1B). C086 was dissolved in DMSO as a stock solution and diluted in culture media. Gefitinib was purchased from LC Laboratories (Woburn, MA, USA). Anti-Hsp90, anti- $\beta$-actin, anti-EGFR, anti-Ras, anti-CRaf, anti-Akt, anti-P-Akt, anti-Mek, anti-P-Mek, antiErk $1 / 2$, anti-P-Erk, anti-C-Myc anti-Bax, anti-Bcl-2 (an apoptosis suppression protein), caspase- 8 , cleaved caspase-8, and the Apoptosis Antibody Sampler Kit containing PARP, cleaved PARP, caspase-9, cleaved caspase-9, caspase-3, cleaved caspase-3, caspase-7, cleaved caspase7 were purchased from Cell Signaling Technology, Inc (Danvers, MA, USA). Annexin-V-APC/PI Apoptosis Detection Kit was purchased from Nanjing Keygen Biotech Co. Ltd (Nanjing, China). Propidium iodide (PI) was obtained from Sigma Aldrich.

\section{Fluorescence Measurements}

Samples were excited at $280 \mathrm{~nm}$ and fluorescence intensities were recorded from 290 to $500 \mathrm{~nm}$ at $37^{\circ} \mathrm{C}$ using a Cary Eclipse spectrofluorometer (Varian, Palo Alto, CA, USA). The measurements were obtained with $2.0 \mathrm{~mL}$ of $5.0 \mu \mathrm{mol} /$ L Hsp90 solution (10 mmol/L PBS buffer, $\mathrm{pH} \mathrm{7.6)} \mathrm{and}$ successive additions of $\mathrm{C} 086$ and gefitinib as single agents or in combinations from 5 to $50 \mu \mathrm{mol} / \mathrm{L}$. The binding interaction of $\mathrm{C} 086$ and gefitinib as single agents or in combinations with Hsp90 was expressed as a value of dissociation constants $\left(\mathrm{K}_{\mathrm{d}}\right)$. All tests were performed in triplicate. ${ }^{24}$

\section{MTT Assays}

Exponentially growing cells $\left(1 \times 10^{4}\right.$ cells $\left./ \mathrm{mL}\right)$ were incubated in triplicate in a clear 96-well plates for $48 \mathrm{hrs}$ at $37^{\circ} \mathrm{C}$ and treated with varying concentrations of $\mathrm{C} 086$ and gefitinib as single agents or in combinations dissolved in culture medium. Control cells were exposed to the medium and then 3-(4,5-dimethylthiazol-2-yl)-2,5-diphenyltetrazolium bromide (MTT; Sigma Chemical Company, St Louis, MO, USA) solution $(5 \mathrm{mg} / \mathrm{mL})$ was added and incubated for 4 hrs. The dark blue formazan crystals were solubilized in DMSO and the optical density was detected at $570 \mathrm{~nm}$ with a spectrophotometer. Cell viability was assessed by the MTT assays. Growth inhibition rate was calculated according to mean values obtained from each concentration relative to control values, and the half maximal inhibitory concentrations (IC50) were calculated by PASW Statistics 18 (SPSS, Inc).

\section{CFSE Staining Assays}

Exponentially growing cells were resuspended in the CFSE (carboxyfluorescein diacetate succinimidyl ester) staining solution at $37^{\circ} \mathrm{C}$ for 10 mins. After washing with cold RPMI-1640 medium containing 10\% heat-inactivated FBS, cells were grown in 6-well plates at a final concentration of $8 \times 10^{4}$ cells/well in the presence or absence of $\mathrm{C} 086$ and gefitinib as single agents or in combinations for $72 \mathrm{hrs}$ at $37^{\circ} \mathrm{C}$. The cells were resuspended in PBS and then analyzed by flow cytometry.

\section{Apoptosis Assessment By Annexin-V Staining}

The Annexin V-APC/PI Apoptosis Detection Kit (Nanjing, China) was used for the apoptosis assay according to the manufacturer's instructions. Briefly, A549 cells and NCIH1975 cells were treated with gefitinib, C086 or gefitinib plus C086 for $48 \mathrm{hrs}$. Subsequently, the NSCLC cells were resuspended in $100 \mu \mathrm{L}$ of staining solution containing Annexin-V-APC/PI in buffer. After incubation at room temperature for 15 mins in the dark, cells were analyzed immediately using a flow cytometer (BD FACSCalibur, BD Biosciences, Franklin, NJ, USA). Annexin-V bound to cells that expressed phosphatidylserine on the outer layer of the cell membrane. Cells that stained positive for Annexin-V were scored as apoptotic cells. ${ }^{25}$

\section{Cell Cycle Assessment By PI Staining}

Following the drug treatments, the cells were resuspended in PBS and fixed with $70 \%$ ethanol overnight at $-20^{\circ} \mathrm{C}$. After washing with cold PBS, cells were incubated with DNase-free RNase and propidium iodide (PI) staining at $37^{\circ} \mathrm{C}$ for 30 mins. Then, cells were analyzed immediately by flow cytometry.

\section{Western Blot Analysis}

The cancer cells were treated with compounds at indicated doses for $48 \mathrm{hrs}$, then washed with cold PBS and harvested with NP-40 lysis buffer containing protease inhibitor and phosphatase inhibitor. The cleared cell lysates were loaded and separated by sodium dodecyl sulfate polyacrylamide gel electrophoresis (SDS-PAGE). After electrophoresis, the proteins were transferred to a PVDF membrane $\left(150 \mathrm{~mA}, 4^{\circ} \mathrm{C}\right)$ 
for $1.5 \mathrm{hrs}$. The membranes were blocked in blocking buffer (1\% BSA, Tris-HCl 20 mmol/L, pH 7.5, NaCl 150 mmol/L, and $0.05 \%$ Tween-20) for $1 \mathrm{hrs}$ at RT, followed by incubation with the relevant antibody overnight at $4{ }^{\circ} \mathrm{C}$. After binding of anti-rabbit peroxidase-conjugated secondary IgG antibodies, the membranes were visualized by ECL chemiluminescence according to the instructions of the manufacturer (Thermo Scientific, Waltham, MA, USA). The membranes were scanned on a Carestream Image Station System to visualize the bands.

\section{Statistical Analysis}

Statistical analysis of the data was performed with twosided unpaired $t$-tests using the GraphPad software package for Windows (Prism version 7.0) and Origin 8.5 software. Values are reported as the mean values of triplicate or duplicate experiments. Differences were considered statistically significant at $\mathrm{P}<0.05$.

\section{Results}

\section{C086 Combined With Gefitinib Damages The Molecular Chaperone Functions Of Hsp90 In NSCLC Cells}

The binding of C086, gefitinib and the combinations to Hsp90 was characterized by fluorescence quenching experiments. When Hsp90 was incubated with increasing concentrations of C086, gefitinib, or C086 plus gefitinib, the fluorescence intensity gradually decreased (Figure 1B). Using the equation previously described, ${ }^{26}$ the titration curves for Hsp90 yielded estimated dissociation constants $\left(\mathrm{K}_{\mathrm{d}}\right) . \mathrm{K}_{\mathrm{d}}$ values were determined to be $18.62 \pm 0.27 \mu \mathrm{mol} / \mathrm{L}$, $8.52 \pm 0.25 \mu \mathrm{mol} / \mathrm{L}$ and $6.55 \pm 0.12 \mu \mathrm{mol} / \mathrm{L}$, respectively (Figure 1C).

\section{Treatment With C086 And Gefitinib In Combination Results In Synergistically Inhibit Proliferation Of NSCLC Cells}

The feasibility of combining C086 with gefitinib in two NSCLC cell lines was assessed through a series of proliferation assays. First, we examined the single and additive effects on proliferation of A549 and NCI-H1975 cell lines. A549 cells were treated with C086, gefitinib, or C086 plus gefitinib ranging from 0.625 to $40 \mu \mathrm{mol} / \mathrm{L}$, while NCIH1975 cells were incubated with C086 and gefitinib as single agents or in combinations ranging from 0.625 to 40 $\mu \mathrm{mol} / \mathrm{L}$. The IC50 values of C086 for the A549 and NCl-
H1975 cell lines were $5.13 \pm 1.08$ and $2.97 \pm 0.12 \mu \mathrm{mol} / \mathrm{L}$, respectively. Potential synergism between C086 and gefitinib in NSCLC cell lines was evaluated by the ChouTalalay method, which is widely employed in drug combination and synergy quantification. ${ }^{27}$ The resulting combination index $(\mathrm{CI})$ theorem offers quantitative definitions for additive effect $(\mathrm{CI}=1)$, synergism $(\mathrm{CI}<1)$ and antagonism $(\mathrm{CI}>1)$ in drug combinations. ${ }^{27}$ Effect of the optimal combinative concentrations obtained from Chou-Talalay method on the NSCLC cell viability was tested by MTT assay. Results from Figure 2A showed C086 is a more potent inhibitor of two NSCLC cells than gefitinib and a significantly synergic growth inhibition by the drug combinations in vitro in A549 $(\mathrm{CI}=0.393)$ and NCI-H1975 $(\mathrm{CI}=0.304)$ cell lines compared with single drugs.

To gain a better understanding of the mechanism of inhibition, we determined the single and addictive effects of treatment with C086 and gefitinib on the downstream PI3K/Akt and Ras-Raf-Erk signaling pathway. Exposure of A549 and NCI-H1975 cells to C086 or C086 plus gefitinib resulted in reduction of $\mathrm{Hsp} 90$ client proteins, such as EGFR, Raf, Akt, Erk and C-Myc. Of particular interest was the observed decrease in their phosphorylated forms in a similar manner (Figure 2B). The results indicated a synergistic blockade downstream signaling by combined treatment of $\mathrm{C} 086$ and gefitinib, with NCIH1975 cells showing much greater sensitivity to C086 and the combinations than A549 cells.

\section{C086 Cotreatment With Gefitinib Induces Cell Cycle Arrest In Both A549 And $\mathrm{NCl}-\mathrm{HI} 975$ Cells}

The inhibition of A549 or NCI-H1975 cell proliferation by C086 and gefitinib as a single agent or in combinations was also shown by CFSE staining assay (Figure 3A) in order to gain further insight into the effects of $\mathrm{C} 086$ with gefitinib on cell proliferation. These results indicated that both NSCLC cells were also sensitive to C086, gefitinib and the compound. Since the combination disrupts cell growth, we next studied the single and additive effects on the cell cycle distribution of A549 and NCI-H1975 cell lines. Significant $\mathrm{G}_{0} / \mathrm{G}_{1}$ phase cell cycle arrest was observed in conditions treated with gefitinib compared to controls, while treatment with $\mathrm{C} 086$ alone showed $\mathrm{G}_{2} / \mathrm{M}$ phase cell cycle arrest at $24 \mathrm{hrs}$. These results indicated that C086-treated cells were more efficient at inducing $\mathrm{G}_{2} / \mathrm{M}$ phase arrest both in A549 and in NCI-H1975 cells 


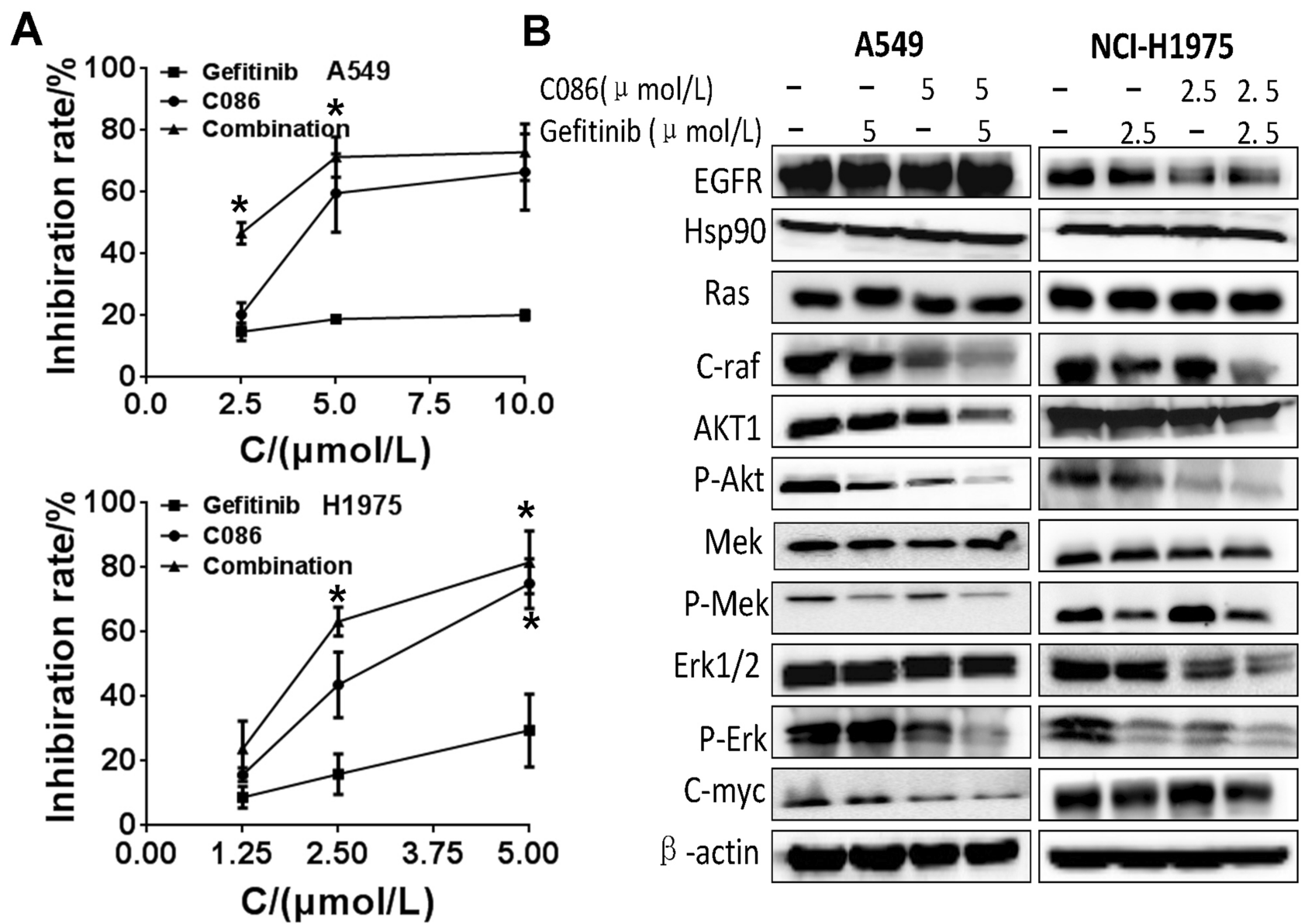

Figure 2 C086 and gefitinib as single agents or in combinations inhibit the proliferation of NSCLC cells. (A) A549 cells were treated by C086 and gefitinib as single agents or in combinations ranging from 2.5 to $10 \mu \mathrm{mol} / \mathrm{L}$ for $48 \mathrm{hrs}$, while $\mathrm{NCl}-\mathrm{H} I 975$ cells were incubated with $\mathrm{C} 086$ and gefitinib as single agents or in combinations at I.25, 2.5 and $5.0 \mu \mathrm{mol} / \mathrm{L}$. Cell-growth inhibition was assessed by an MTT assay. The data were shown as mean $\pm \mathrm{SEM}(\mathrm{n}=3$; $* \mathrm{P}<0.05)$. The error bars represent the SEM. (B) The synergistic inhibition of $\mathrm{A} 549$ and $\mathrm{NCl}-\mathrm{H} 1975$ cells treated with $\mathrm{C} 086$, gefitinib or $\mathrm{C} 086$ plus gefitinib were monitored by Western blot. A549 and $\mathrm{NCl}-\mathrm{HI} 975$ cells were treated with C086, gefitinib or C086 plus gefitinib at 5.0 and $2.5 \mu \mathrm{mol} / \mathrm{L}$, respectively. $\boldsymbol{\beta}$-actin antibody was used as loading control.

(Figure 3B and C). Interestingly, cells treated with the combination of $\mathrm{C} 086$ and gefitinib showed induced $\mathrm{G}_{2} / \mathrm{M}$ phase cell cycle arrest.

\section{C086 Combined With Gefitinib Shows Synergistic Apoptotic Effect In NSCLC Cells}

To determine whether the growth inhibition of A549 and NCI-H1975 cells by C086 with gefitinib is associated with the induction of apoptosis, we used AnnexinV-APC/PI staining and quantified the number of compound-induced apoptosis in A549 and NCI-H1975 cells. Consistent with the cellular proliferation assay results, apoptosis was induced in both A549 and NCI-H1975 cells (Figure 4A and B). Mechanism underlying the synergistic anticancer effects of the combination treatment with C086 and gefitinib was determined by measuring the levels of apoptosisrelated proteins, including PARP, cleaved PARP, caspase-9, cleaved caspase-9, caspase-3, cleaved caspase-3, caspase-8, cleaved caspase-8, caspase-7, cleaved caspase-7, Bcl-2 and Bax in A549 and NCI-H1975 cells treated with gefitinib (5.0 and $2.5 \mu \mathrm{mol} / \mathrm{L}$ ), C086 (5.0 and $2.5 \mu \mathrm{mol} / \mathrm{L}$ ) or their combination for $48 \mathrm{hrs}$ by performing Western blotting analysis. We found that C086 induces apoptosis through caspase pathway, and levels of cleaved PARP, cleaved caspase-9, cleaved caspase-3, cleaved caspase- 8 and cleaved caspase-7 significantly increased in cells treated with the combination of C086 and gefitinib compared with those in cells treated with gefitinib or C086 alone (Figure 4C). Therefore, C086 in combination with gefitinib enhanced cell death which is an important feature in NSCLC cells.

\section{Discussion}

The main aims of drug combination are to achieve synergistic therapeutic effect, dose and toxicity reduction and to 

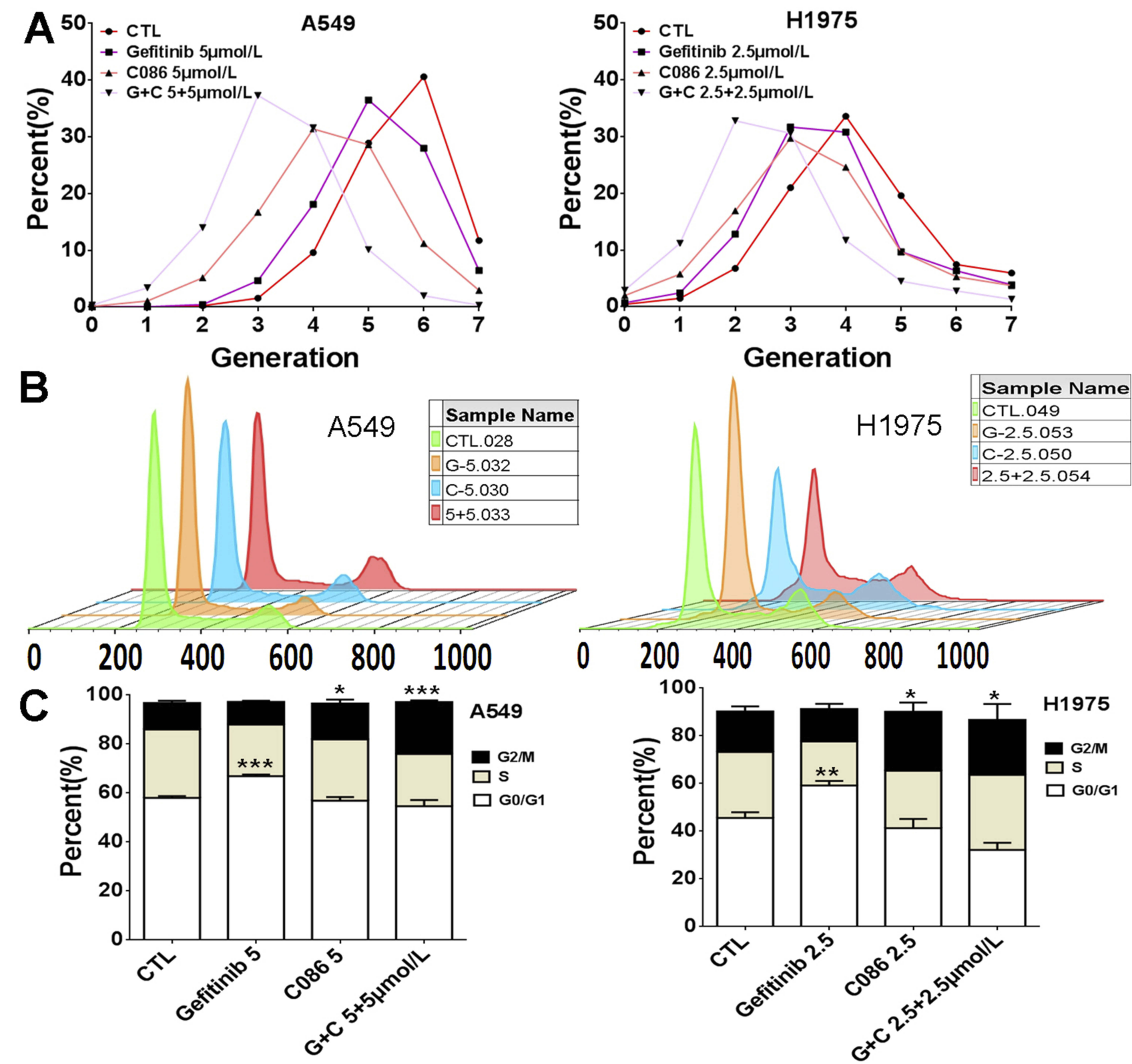

Figure $3 \mathrm{C} 086$ and gefitinib as single agents or in combinations inhibits the growth of A549 and NCl-HI975 cells. (A) A549 and NCl-HI975 cells were stained with CFSE and then were treated with C086, gefitinib or C086 plus gefitinib at the indicated concentrations for 72 hrs, harvested and subsequently analyzed by flow cytometry. (B-C) $\mathrm{C} 086$ and gefitinib as single agents or in combinations induce cell cycle arrest in NSCLC cells. A549 and NCl-HI975 cells were treated with C086, gefitinib or C086 plus gefitinib at the indicated concentrations for $24 \mathrm{hrs}$, harvested and fixed with $70 \%$ ethanol overnight at $-20^{\circ} \mathrm{C}$, harvested, stained with $\mathrm{Pl}$ and subsequently analyzed by flow cytometry. $* \mathrm{P}<0.05, * * \mathrm{P}<0.01$, $* * * \mathrm{P}<0.001$ vs. control.

minimize or delay the induction of drug resistance. ${ }^{28}$ Since curcumin displayed synergistic effects of several chemotherapeutic drugs, it has been suggested as an adjuvant for anticancer therapy. ${ }^{29-31}$ In the present work, we investigated the mechanisms of curcumin derivative, C086, in overcoming primary and acquired resistance to gefitinib in NSCLC with different EGFR status. We discovered that the combination of $\mathrm{C} 086$ and gefitinib displayed synergistic inhibition of proliferation and enhanced antitumor effects in two NSCLC cell lines (A549 and NCI-H1975 cells) in vitro. This was accompanied by more significant apoptotic cell death and augmented blockade of EGFR downstream signaling pathways as compared with monotherapy, irrespective of different resistance mechanisms.

It is now widely accepted that EGFR is a validated therapeutic target in NSCLC. Mutated EGFR and the mature, wild-type receptor that overexpress WT-EGFR are bona fide Hsp90 clients in cancer. ${ }^{32-34}$ We show here that two subtypes of NSCLC cells are inhibited in their proliferation by $\mathrm{C} 086$ as a single agent in a dose- 


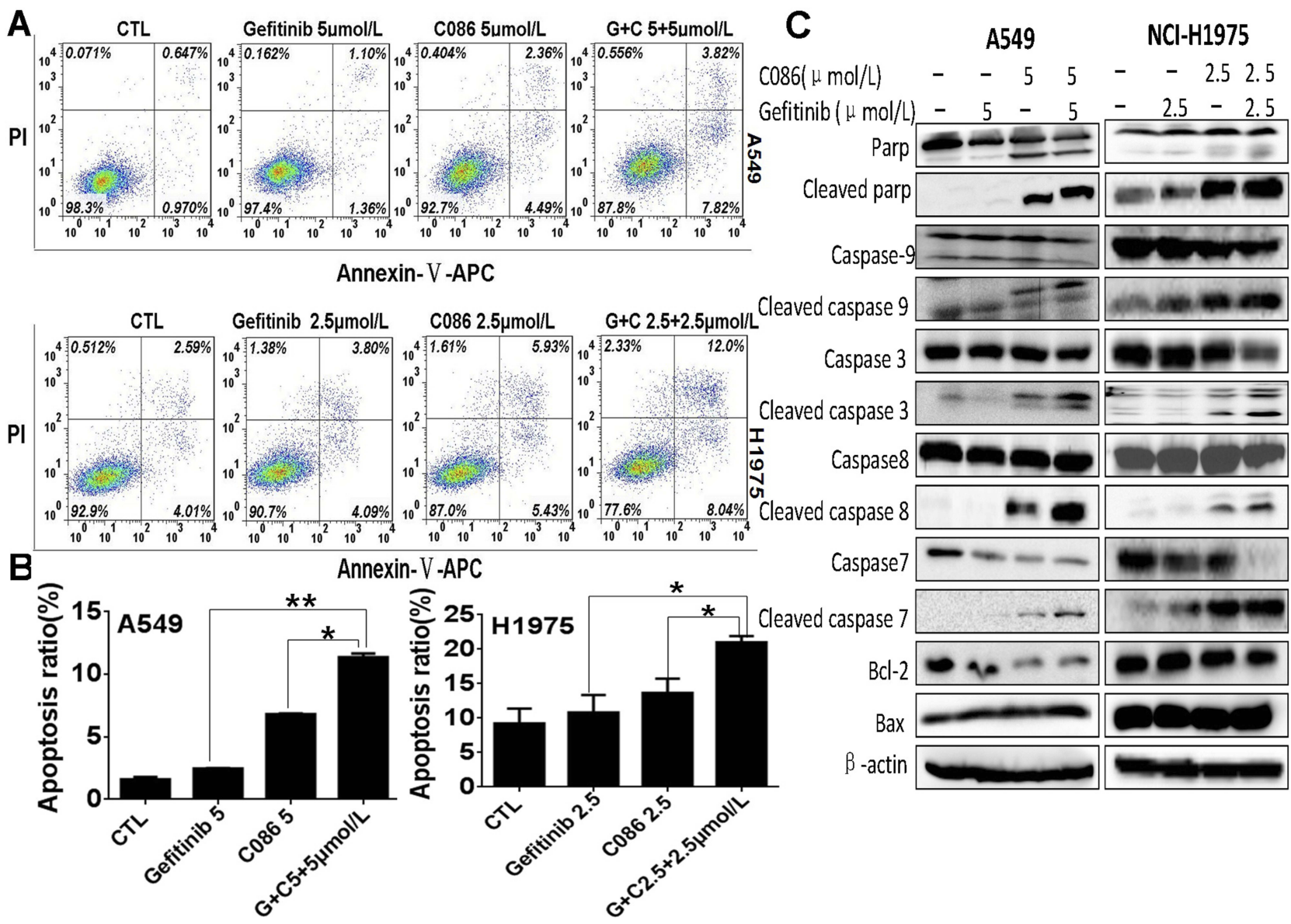

Figure 4 Effect of $\mathrm{C} 086$ and gefitinib as single agents or in combinations on the induction of apoptosis in NSCLC cells. (A) A549 and NCl-HI975 cells were cultured in the presence of gefitinib, C086 or gefitinib plus C086 at the indicated concentrations for 48 hrs, harvested, double stained with Annexin-V-APC and PI and subsequently analyzed by a flow cytometer. Quantification of apoptotic staining is indicated for each condition. (B) Significant differences between gefitinib, C086 and gefitinib plus C086 treatment groups are indicated. The results represent the mean \pm SEM of triplicate experiments. $(n=3, * P<0.05$, **P $<0.01)$. (C) The protein levels of PARP, cleaved PARP, caspase-9, cleaved caspase-9, caspase-3, cleaved caspase-3, caspase-8, cleaved caspase-8, caspase-7, cleaved caspase-7, Bcl-2 and Bax in A549 and NCl-HI975 cell lysis were determined by protein gel blot. $\beta$-actin antibody was used as loading control.

dependent manner. Furthermore, the combination of C086 with gefitinib exhibited synergistic enhancement of the antitumor activity (Figure 2A). C086 alone and in combination with gefitinib treatment inhibit the proliferation of A549 and NCI-H1975 cells through the downregulation of EGFR signal transduction pathway, such as PI3K/Akt and Ras-Raf-Erk signaling pathway, with NCI-H1975 cells showing much greater sensitivity to $\mathrm{C} 086$ and the combinations than A549 cells (Figure 2B). These results suggest that a more complete and sustained inhibition of EGFR can occur through inhibition of the Hsp90 chaperon pathway. Although the traditional Hsp90 inhibitors, such as geldanamycin (GA) and its derivative 17-allyamino-geldanamycin (17AAG), have exhibited potent anticancer effects, severe hepatotoxicity has prevented their clinical development. ${ }^{35}$ Treatment with C086 showed a more favorable safety profile during the whole experimental periods in the previous study. ${ }^{23}$ Combination therapy displayed significantly enhanced antitumor efficacy and reduced toxicity compared with gefitinib alone.

Moreover, the data presented here suggest that the capacity of $\mathrm{C} 086$ to potentiate the in vitro activity of gefitinib provides a compelling rationale for combining two agents as part of novel treatment strategies for NSCLC. Overall, the therapeutic benefit conferred by dual Hsp90/EGFR TKI blockade was conserved within both the mutant and WT-EGFR disease settings, thus providing new opportunities to target EGFR and overcome mechanisms of resistance across diverse groups of NSCLC patients.

\section{Conclusion}

As a novel Hsp90 inhibitor, C086 alone or in combination with gefitinib shows potent antitumor effects in NSCLC 
cells in vitro. The combination of C086 and gefitinib displayed synergistic PI3K/Akt and Ras-Raf-Erk signaling depression, suggesting a promising strategy in treating NSCLC.

\section{Acknowledgments}

This work was funded by Fujian Provincial Health and Family Planning Commission of China (2016-1-33), the Startup Fund for Scientific Research, Fujian Medical University (2017XQ1133), the Joint Funds for the Innovation of Science and Technology, Fujian province, China (2016Y9059), the Projects of Industry-Academy Cooperation for Science, Technology of Fujian Province, China (2016Y4005) and the Open Research Fund of State Key Laboratory of Cellular Stress Biology, Xiamen University (SKLCSB2017KF003). Liman Wang and Yingjuan Fan are co-first authors for this study.

\section{Disclosure}

The authors report no conflicts of interest in this work.

\section{References}

1. Siegel RL, Miller KD, Jemal A. Cancer statistics, 2018. CA Cancer J Clin. 2018;68(1):7-30. doi:10.3322/caac.21442

2. Chen W, Zheng R, Baade PD, et al. Cancer statistics in China, 2015. CA Cancer J Clin. 2016;66(2):115-132. doi:10.3322/caac.21338

3. Ourari-Dhahri B, Ben Slima H, Ben Amar J, et al. Management of non small cell lung cancer. Tunis Med. 2012;90(12):847-851.

4. Ramalingam SS, Owonikoko TK, Khuri FR. Lung cancer: new biological insights and recent therapeutic advances. CA Cancer $J$ Clin. 2011;61(2):91-112. doi:10.3322/caac.20102

5. Levitzki A. EGF receptor as a therapeutic target. Lung Cancer. 2003;41:S9-S14. doi:10.1016/S0169-5002(03)00134-X

6. Ferrazzi A, Russo I, Pasello G, Alaibac M. Atypical skin reaction in a patient treated with gefitinib for advanced lung cancer: a case report and review of the literature. Exp Ther Med. 2016;11(1):197-200. doi:10.3892/etm.2015.2881

7. Codony-Servat C, Codony-Servat J, Karachaliou N, et al. Activation of signal transducer and activator of transcription 3 (STAT3) signaling in EGFR mutant non-small-cell lung cancer (NSCLC). Oncotarget. 2017;8 (29):47305-47316. doi:10.18632/oncotarget.17625

8. Al Mamun Bhuyan A, Wagner T, Cao H, Lang F. Triggering of suicidal erythrocyte death by gefitinib. Cell Physiol Biochem. 2017;41(4):1697-1708. doi:10.1159/000471823

9. Sharma SV, Bell DW, Settleman J, Haber DA. Epidermal growth factor receptor mutations in lung cancer. Nat Rev Cancer. 2007;7 (3):169-181. doi:10.1038/nrc2088

10. Pao W, Wang TY, Riely GJ, et al. KRAS mutations and primary resistance of lung adenocarcinomas to gefitinib or erlotinib. PLoS Med. 2005;2(1):57-62. doi:10.1371/journal.pmed.0020017

11. Wegele H, Müller L, Buchner J. Hsp70 and Hsp90-a relay team for protein folding. Rev Physiol Biochem Pharmacol. 2004;151:1-44. doi:10.1007/s10254-003-0021-1

12. Richter K, Hendershot LM, Freeman BC. The cellular world according to Hsp90. Nat Struct Mol Biol. 2007;14(2):90-94. doi:10.1038/ nsmb0207-90
13. Workman P, Burrows F, Neckers L, Rosen N. Drugging the cancer chaperone HSP90: combinatorial therapeutic exploitation of oncogene addiction and tumor stress. Ann N Y Acad Sci. 2007;1113 (1):202-216. doi:10.1196/annals.1391.012

14. Isaacs JS, Xu W, Neckers L. Heat shock protein 90 as a molecular target for cancer therapeutics. Cancer Cell. 2003;3(3):213-217.

15. Neckers L, Workman P. Hsp90 molecular chaperone inhibitors: are we there yet? Clin Cancer Res. 2012;18(1):64-76. doi:10.1158/10780432.CCR-11-1000

16. Neckers L. Heat shock protein 90: the cancer chaperone. J Biosci. 2007;32(3):517-530.

17. Xu W, Neckers L. Targeting the molecular chaperone heat shock protein 90 provides a multifaceted effect on diverse cell signaling pathways of cancer cells. Clin Cancer Res. 2007;13(6):1625-1629. doi:10.1158/1078-0432.CCR-06-2270

18. Trepel J, Mollapour M, Giaccone G, Neckers L. Targeting the dynamic HSP90 complex in cancer. Nat Rev Cancer. 2010;10 (8):537-549. doi:10.1038/nrc2887

19. Gallegos Ruiz MI, Floor K, Roepman P, et al. Integration of gene dosage and gene expression in NSCLC, identification of Hsp90 as potential target. PLoS One. 2008;3(3):e0001722. doi:10.1371/journal. pone. 0001722

20. Chen C, Liu Y, Chen YZ, Xu JH. C086, a novel analog of curcumin, induces growth inhibition and down-regulation of $\mathrm{NF \kappa B}$ in colon cancer cells and xenograft tumors. Cancer Biol Ther. 2011;12 (9):797-807. doi:10.4161/cbt.12.9.17671

21. Huang W, Ye M, Zhang LR, et al. FW-04-806 inhibits proliferation and induces apoptosis in human breast cancer cells by binding to $\mathrm{N}$ terminus of Hsp90 and disrupting Hsp90-Cdc37 complex formation. Mol Cancer. 2014;13(1):150. doi:10.1186/1476-4598-13-150

22. Wu LX, Yu J, Chen RJ, et al. Dual inhibition of Bcr-Abl and Hsp90 by $\mathrm{C} 086$ potently inhibits the proliferation of imatinib-resistant CML cells. Clin Cancer Res. 2015;21(4):833-843. doi:10.1158/1078-0432. CCR-13-3317

23. Huang W, Wu QD, Zhang M, et al. Novel Hsp90 inhibitor FW-04806 displays potent antitumor effects in HER2-positive breast cancer cells as a single agent or in combination with lapatinib. Cancer Lett. 2015;356(2):862-871. doi:10.1016/j.canlet.2014.10.040

24. Gao PZ, Wu H, Guo J, Xu YM. Study on the interaction between breviscapinum and bovine serum albumin by fluorescence spectrometry. Chin JMAP. 2012;29(2):106-109. doi:10.13748/j.cnki. issn1007-7693.2012.02.025

25. Meng A, Wang Y, Brown SA, Van Zant G, Zhou DH. Ionizing radiation and busulfan inhibit murine bone marrow cell hematopoietic function via apoptosis-dependent and -independent mechanisms. Exp Hematol. 2003;31(12):1348-1356. doi:10.1016/j.exphem

26. Chen JJ, Guo QJ, He XM, Yang SX, Chen C, Zhang LR. Study on a screening model for inhibitor of Hsp90 ATPase activity. J Xiamen Univ. 2010;49(5):711-716.

27. Chou TC. Drug combination studies and their synergy quantification using the Chou-Talalay method. Cancer Res. 2010;70(2):440-446. doi:10.1158/0008-5472.CAN-09-1947

28. Chou TC. Theoretical basis, experimental design, and computerized simulation of synergism and antagonism in drug combination studies. Pharmacol Rev. 2006;58(3):621-681. doi:10.1124/pr.58.3.10

29. Patel BB, Sengupta R, Qazi S, et al. Curcumin enhances the effects of 5 -fluorouracil and oxaliplatin in mediating growth inhibition of colon cancer cells by modulating EGFR and IGF-1R. Int $J$ Cancer. 2008;122(2):267-273. doi:10.1002/ijc.23097

30. Kamat AM, Sethi G, Aggarwal BB. Curcumin potentiates the apoptotic effects of chemotherapeutic agents and cytokines through downregulation of nuclear factor- $\mathrm{\kappa B}$ and nuclear factor- $\mathrm{\kappa B}$-regulated gene products in IFN- $\alpha$-sensitive and IFN- $\alpha$-resistant human bladder cancer cells. Mol Cancer Ther. 2007;6(3):1022-1030. doi:10.1158/15357163.MCT-06-0545 
31. Sung B, Kunnumakkara AB, Sethi G, et al. Curcumin circumvents chemoresistance in vitro and potentiates the effect of thalidomide and bortezomib against human multiple myeloma in nude mice model. $\mathrm{Mol}$ Cancer Ther. 2009;8(4):959-970. doi:10.1158/1535-7163.MCT-08-0905

32. Shimamura T, Lowell AM, Engelman JA, Shapiro GI. Epidermal growth factor receptors harboring kinase domain mutations associate with the heat shock protein 90 chaperone and are destabilized following exposure to geldanamycins. Cancer Res. 2005;65(14):64016408. doi:10.1158/0008-5472.CAN-05-0933

33. Shimamura T, Li DN, Ji HB, et al. Hsp90 inhibition suppresses mutant EGFR-T790M signaling and overcomes kinase inhibitor resistance. Cancer Res. 2008;68(14):5827-5838. doi:10.1158/00085472.CAN-07-5428
34. Ahsan A, Ramanand SG, Whitehead C, et al. Wild-type EGFR is stabilized by direct interaction with HSP90 in cancer cells and tumors. Neoplasia. 2012;14(8):670-677. doi:10.1593/neo.12986

35. Supko JG, Hickman RL, Grever MR, Malspeis L. Preclinical pharmacologic evaluation of geldanamycin as an antitumor agent. Cancer Chemother Pharmacol. 1995;36(4):305-315. doi:10.1007/BF00689048

\section{Publish your work in this journal}

Cancer Management and Research is an international, peer-reviewed open access journal focusing on cancer research and the optimal use of preventative and integrated treatment interventions to achieve improved outcomes, enhanced survival and quality of life for the cancer patient.

Submit your manuscript here: https://www.dovepress.com/cancer-management-and-research-journal
The manuscript management system is completely online and includes a very quick and fair peer-review system, which is all easy to use. Visit http://www.dovepress.com/testimonials.php to read real quotes from published authors. 